\title{
Discounting, Preferences, and Paternalism in Cost-Effectiveness Analysis
}

\author{
Gustav Tinghög
}

\section{Linköping University Post Print}

N.B.: When citing this work, cite the original article.

The original publication is available at www.springerlink.com:

Gustav Tinghög, Discounting, Preferences, and Paternalism in Cost-Effectiveness Analysis, 2012, Health Care Analysis, (20), 3, 297-318.

http://dx.doi.org/10.1007/s10728-011-0188-6

Copyright: Springer Verlag (Germany)

http://www.springerlink.com/?MUD=MP

Postprint available at: Linköping University Electronic Press

http://urn.kb.se/resolve?urn=urn:nbn:se:liu:diva-65394 


\title{
Discounting, Preferences, and Paternalism in Cost-
}

\section{Effectiveness Analysis}

\author{
Author: Gustav Tinghög, PhD. ${ }^{1,2}$
}

1. Division of Economics, Department of Management and Engineering, Linköping

University, Sweden

2. Division of Health Care Analysis, Department of Medical and Health Sciences, Linköping

University, Sweden

Running Head: Legitimate basis for discounting

\section{Corresponding Author:}

Gustav Tinghög

Department of Management and Engineering

Linköping University

SE-581 83 Linköping

Sweden

Email: gustav.tinghog@liu.se

Phone: +4613221751

Fax: +46 13224995 
Legitimate basis for discounting

\begin{abstract}
When assessing the cost effectiveness of health care programmes, health economists typically presume that distant events should be given less weight than present events. This article examines the moral reasonableness of arguments advanced for positive discounting in costeffectiveness analysis both from an intergenerational and an intrapersonal perspective and assesses if arguments are equally applicable to health and monetary outcomes. The article concludes that behavioral effects related to time preferences give little or no reason for why society at large should favour the present over the future when making intergenerational choices regarding health. The strongest argument for discounting stems from the combined argument of diminishing marginal utility in the presence of growth. However, this hinges on the assumption of actual growth in the relevant good. Moreover, current modern democracy may be insufficiently sensitive to the con- cerns of future generations. The second part of the article categorises preference failures (which justify paternalistic responses) into two distinct groups, myopic and acratic. The existence of these types of preference failures makes elicited time preferences of little normative relevance when making decisions regarding the social discount rate, even in an intrapersonal context. As with intergenerational discounting, the combined arguments of growth and diminishing marginal utility offer the strongest arguments for discounting in the intrapersonal context. However, there is no prima facie reason to assume that this argument should apply equally to health and monetary values. To be sure, selecting an approach towards discounting health is a complex matter. However, the life-ordeath implications of any approach require that the discussion not be downplayed to merely a technical matter for economists to settle.
\end{abstract}

Keywords Discounting Cost-effectiveness analysis Paternalism Preference failures Time preferences 


\section{Discounting, Preferences, and Paternalism in Cost- Effectiveness Analysis}

\section{Introduction}

When conducting cost-effectiveness analysis (CEA), discounting enables policymakers to compare competing health programmes that entail intertemporal trade-offs between present and future values, typically by assigning less value to future events in comparison to events closer to the present. Although the discount rate is a crucial parameter in CEA, it is often employed arbitrarily and with little or no explicit justification. As Krahn and Gafni [18] remark: "Most analyses, including those who take great care to measure costs and consequences, pull their discount rates either out of the air or off the shelf, and the lucky number is most often 5\%." (p. 415). The widespread lack of explicit justification reflects persistent disagreement about the legitimate basis for discounting future events, a debate that has lasted for decades (e.g. [1,25,27]). The discipline of discounting has thus become a battleground where heavyweight intellectuals from different academic fields wield powerful and impressively diverse arguments. It has also become a discipline for great soliloquists skilled at presenting their own arguments, but less prone to consider others.

Against the background of widespread disagreement, this article begins by categorising the rationales advanced for discounting health into two distinct theoretical groups based on Ramsey's [28] formalisation of the social discount rate. Thereby, I intend to address three recurrent questions with particular relevance in the context of applied cost-effectiveness analysis: i) Which of the motives outlined in the literature constitute morally legitimate reasons for discounting future values in CEA?; ii) Do these motives apply differently when making intertemporal valuations in comparing health to wealth?; and iii) To what extent should the social discount rate used in CEA incorporate considerations for individuals' time preferences?

The main conclusion of this article is that the behavioral effects related to time preferences advanced in the literature provide little or no reason why society at large should favour the present over the future when making intergenerational choices regarding health. From a fairness perspective it seems impermissible that society should favour current over future generations purely on the basis of position in time. Moreover, contemporary democracy may 
be insufficiently sensitive to the concerns of future generations, rendering a paternalistic approach towards the social discount rate preferable. However, the fact that behavioural effects give little support to discounting future health does not mean that discounting in CEA should be abandoned altogether. Factors such as growth and diminishing marginal utility, which are likely to change as functions of temporal distance, may still justify assigning less value to future outcomes. This does not mean that temporal distance in itself offers any legitimate reason for discounting, and there is no prima facia reason to assume that these factors should apply equally to health and money. For intrapersonal, intertemporal choices regarding health, the issues of rationality and justifiable forms of paternalism become more apparent aspects when discussing the normative relevance of individuals' time preferences. This article categorises preference failures, which justify paternalistic intervention, into two distinct groups, myopic and acratic. The existence of these types of preference failures renders elicited time preferences of little normative relevance when making decisions regarding the social discount rate. Some factors of individuals' time preferences, such as dread and anticipation, could however potentially constitute a legitimate basis for discounting in the intrapersonal context once these have been separated from myopic and acratic elements.

Another important argument concerning the relevant basis for social discounting will also be presented, specifically: Although uncertainty is a valid reason for assigning less value to future outcomes, it should not be dealt with through the discount factor since this mis-states our moral view - future events are not less important, but less likely. From a methodological perspective, incorporating uncertainty as a basis for social discounting would result in double counting since life tables and uncertainty parameters included in CEA are supposed to take the likelihood of future events into account.

The article is divided into six sections: Section one introduces the discounted utility (DU) model to illustrate how discounting works in an applied context. Section two follows the structure of Ramsey's formula for the social discount rate to outline the common rationales for discounting future health, based on arguments related to time preferences. Section three continues by outlining the common arguments advanced on the basis of growth and diminishing marginal utility. Section 3 and 4 are purely descriptive and the validity of the presented arguments (and their counterarguments) are not discussed until section five. Thus, section five builds on the preceding sections as it transcends into analysing and justifying 
rationales advanced for discounting future health as opposed to monetary outcomes in CEA. Section six discusses the extent to which the social discount rate should incorporate considerations for individuals' time preferences for health, and presents some original ideas for when paternalism could be justified. The article concludes with some non-utilitarian remarks concerning the DU model and CEA.

\section{Formal models of discounting}

Frank Ramsey [28] presented one of the earliest formalizations of the wide range of reasons expressed for why resources available in the future should be valued less than the same amount available today. His early formula of the social discount rate offers a good starting point for exploring the normative basis for discounting future health:

Social discount rate: $\mathrm{D}=\delta+\varepsilon_{\mathrm{x}} \mathrm{g}_{\mathrm{x}}$

This formula helps distinguish three main components of the rationale for discounting. First, individual time preference $(\delta)$ is motivated by the assumption that individuals are impatient and generally prefer a given amount of resources sooner rather than later. Second, the growth rate of good $\mathrm{x}(\mathrm{g})$ could motivate discounting if society is able to transform resources available today into greater amounts in the future. The third part of the formula, the elasticity of the marginal utility of good $\mathrm{x}(\varepsilon)$, serves as a link between the other two main components. It implies that if there will be more of a good $(x)$ in the future, the utility that an individual derive from a given unit of that good in the future would be less than it is today.

Before exploring the legitimacy these categories of reasons might give to discounting future health, it is important to have an understanding of how intertemporal choices are analyzed in practice. The discounted utility (DU) model is the primary framework through which intertemporal decisions are analysed in economic evaluations today. The model was initially developed by Paul Samuelson [30], who condensed the aforementioned categories of reasons for giving less weight to future resources or events into a single parameter - the discount factor. The DU model makes it possible to calculate overall intertemporal utility simply by multiplying each outcome by a discount factor. Due to the appealing simplicity of the DU model, and its resemblance to the interest rate formula, it quickly became (and remains) the 
standard model for intertemporal public decisions. Formally, the DU model can be expressed as follows:

$$
\begin{aligned}
& U(x)=\sum_{t=0}^{\infty} \delta^{t} U\left(x_{t}\right) \\
& \text { where } \delta^{t}=\frac{1}{1+p}
\end{aligned}
$$

Where, $\mathrm{U}(\mathrm{x})$ represents the utility of outcome $\mathrm{x}, \mathrm{U}\left(\mathrm{x}_{\mathrm{t}}\right)$ represents individuals' instantaneous utility, and $\delta^{\mathrm{t}}$ represents the discount factor, which can vary according to the relative weight placed on utility in period t compared to future periods.. Box 1 further illustrates how the DU model operates in the case of CEA. In words, what the DU model suggests is that future utility should receive less consideration, even though future utility is as certain and intensely experienced.

The general conclusion derived from the empirical literature is that the DU model has little descriptive validity when it comes to describing actual intertemporal behavior among individuals [3,19]. A wide range of experimental studies on time preferences that have displayed numerous anomalies has further confirmed this ${ }^{1}$. For example, it has been observed that people do not appear to discount future outcomes at a rate that is constant over time, but at a rate that is decreasing over time (often referred to as hyperbolic discounting), and that gains tend to be discounted at a higher rate than losses. Although it has been proven that the DU model has little descriptive validity, this does not necessarily imply that it has no normative validity.

To a non-economist discounting might appear to be a merely technical procedure. However, it is important to recognise that discounting implies making decisions about delicate moral issues that have crucial practical implications. For instance, if we apply the DU model and assume that the benefit is lives saved, and we assign a discount factor of $3 \%$, this would mean that we state that 1 life saved today is equivalent to saving 19.2 lives in 100 years. Thus, with a 3\% discount factor it is preferable to save 1 life today rather than 18 lives in 100 years according to the DU model. As Table 1 demonstrates, a larger discount factor is associated

\footnotetext{
${ }^{1}$ For a systematic review of DU anomalies see Fredrick et al [9].
} 


\section{Legitimate basis for discounting}

Box 1 Discounting in cost-effectiveness analysis

The main purpose of cost-effectiveness analysis (CEA) is to provide information about costs and effects summarised in a so-called cost-effectiveness ratio (CE ratio), e.g. cost per additional quality-adjusted life-year (QALY) or cost per additional life-year gained. This CE ratio can be seen as a price estimate for achieving a certain outcome that together with other considerations may help guide policymakers in making decisions on whether or not to implement a new medical treatment (or exclude an old treatment). To do this a present value of future costs must first be calculated using a discount rate. In algebra this can be defined as:

$\mathrm{PV}_{\mathrm{C}}=\sum_{t=0}^{t=\infty} \frac{C_{t}}{(1+i)^{t}}$

Where $\mathrm{C}_{\mathrm{t}}$ measures the cost in year $t$ after the start of the programme and $i$ is the discount rate. Example: A cost of $\$ 100000$ is supposed to occur 5 years ahead. If the discount rate for cost $(i)$ is set at $3 \%$, the present value of this sum will be $\$ 100000 / 1.03^{5}=\$ 86261$. An almost identical formula can be used in calculating the present value for a stream of health effects

$\mathrm{PV}_{\mathrm{H}}=\sum_{t=0}^{t=\infty} \frac{H_{t}}{(1+r)^{t}}$

Here $H_{t}$ measures the health effect in year $t$ after the start of the programme and $r$ is the discount rate. Example: A preventive health care programme will yield a health benefit of 10 QALYs 3 years ahead. If the discount rate for health effects $(r)$ is set at $3 \%$ the present value of this health benefit will be 10 QALY $/ 1.03^{3}=9.15$ QALYs. The CE ratio for a programme is then calculated by dividing $\mathrm{PV}_{\mathrm{C}}(\$ 86261)$ with $\mathrm{PV}_{\mathrm{H}}$ (9.15 QALYs). Hence the CE ratio can be thought of as the average cost per unit of effect ( $\$ 9427$ per QALY in the example). The programme that is the most cost effective is the one that has the lowest average cost per unit of effect. The higher the discount rate applied, the lower the value given to outcomes distant in time.

Table 1 Number of future lives equal to one present life at different discount factors

\begin{tabular}{lrrr}
\hline Years in the future & $\mathbf{3 \%}$ & $\mathbf{5 \%}$ & $\mathbf{1 0 \%}$ \\
\hline 10 & 1.3 & 1.6 & 2.6 \\
50 & 4.4 & 11.5 & 117.4 \\
100 & 19.2 & 131.5 & 13780.6 \\
\hline
\end{tabular}


with giving more weight to the present. Hence, different decisions on discount rates will lead to different recommendations on how to allocate health care resources - recommendations that carry life or death implications. Thus, it is important not to downplay the normative discussion on discounting as merely a technical matter to be settled by health economists 'who know the price of everything but the value of nothing'.

\section{Insert table 1}

\section{Time preferences as a basis for discounting health $(\delta)$}

Two principal behavioural effects have been advanced to explain why individuals' time preferences should ascribe lower value to future benefits: i) the pure time preference effect and ii) the uncertainty effect.

\subsection{Pure time preference}

The first argument, the pure time preference effect, refers solely to the effect of remoteness in time, i.e. individuals generally prefer benefits sooner rather than later, or prefer immediate utility to delayed utility. Already in the economic literature of the $19^{\text {th }}$ century, Eugen von Böhm-Bawerk acknowledged individuals' systematic impatience:

\footnotetext{
We must now consider a /.../ phenomenon of human experience - one that is heavily fraught with consequence. That is the fact that we feel less concerned about future sensations of joy and sorrow simply because they do lie in the future, and the lessening of our concern is in proportion to the remoteness of that future (Cited in [34] p. 74).
}

When considering the concept of pure time preference, it is important to distinguish it from preferences for time discounting, which more broadly include any reason for giving less weight to future events. Pure time preferences refer solely to individuals' degree of impatience and do not take into account any uncertainties about the future or any misguided preferences that individuals might have. People may act impatiently, unaware of the future consequences. This, however, should not be regarded as a case of positive pure time preferences, but of information failure. The concept of pure time preferences simply states 
that I prefer to have $\mathrm{X}$ today rather than having $\mathrm{X}$ at some point in the future, for no other reason than the fact that I dislike waiting.

\section{The arguments of irrationality, intergenerational fairness and personal identity.}

The pure time preference effect as a basis for social discounting of future health has been subjected to a wide array of criticism. First of all there is a common belief (especially among philosophers) that rationality requires temporal neutrality (see e.g, [31,29]). The common argument is that a rational individual should strive towards that life, as a whole, should go a well as possible. Giving more or less weight to utility that occurs in a certain time periods which is implied by pure time preferences - would go against such a goal, and consequently be a case of irrational decision making.

Secondly, it is often argued that pure time preferences is unfair as a basis for social discounting, since it disregards the preferences of future generations. From a fairness perspective it could be argued that a social discount rate should protect future generations from the selfish preferences of current generations - that it is unfair to give higher weight to a health benefit simply because it will benefit "us" instead of "them". Hence, the fact that current generations favour themselves over their descendants should not be considered an ethically valid basis for discounting. Rawls [29], for example, argues that decision makers should not give any weight to mere position in time since individuals would give equal weight to all periods in time if they were behind the veil of ignorance, not knowing to which generation they belong. So, "to achieve a reasonable result, we assume first, that the parties represent family lines, say, who care at least for their more immediate descendants; and second, that the principle adopted must be such that they would wish all earlier generations to have followed it" (p. 255).

The matter of personal identity over time, as proposed most notably by Parfit [26], extends the fairness criticism beyond the case of intergenerational discounting but argues against that pure time preferences should be irrational. In short, the concept of personal identity can be used to link a person in one time period with the same person in a later period. Parfit uses this account of personal identity to contend that there is no long-term self or "I" to which future benefits can be ascribed. Instead, the decrease in psychological connections gives the future self a 
status of other people. For example, a 21-year-old person will - through psychological features such as memory and intent - be closely connected to his actions as a 20-year-old. However, the psychological link between the 20-year-old and his future self as a 60-year-old will be much weaker since his personal identity has changed. He treats his future selves as if they were different individuals to whom he is more or less attached. Consequently, the 20year-old can impose costs on his future self. But the 60-year-old future self has had little influence on the actions his younger self-imposed on him, although he must bear much of the cost. The implication from Parfit's argument on discounting health would be that some degree of shortsighted, pure time preference is rational because individuals become progressively less psychologically attached to their future selves. Therefore, it would not be a sign of irrationality for individuals to act imprudent (e.g excessive drug use) and give future health less weight than their present health if the degree of connectedness with future selves is sufficiently small. In this respect, the utility experienced by our future selves is not fully one's "own". Although diminishing connectedness may make pure time preferences rationally permissible, it may still be morally impermissible according to Parfit, since future self gain status of other people and society may still have ethical obligations towards those people. Parfit thereby possibly extends the intergenerational fairness argument to include future selves as future generations.

The Economic literature on intertemporal choices has largely ignored the topic of personal identity $^{2}$. Among philosophers, however, Parfit's claims about diminishing psychological connectedness with our future selves has received considerable attention and been contested by many (see e.g $[17,36])$. Those who oppose the Parfitian view of personal identity typically argue that personal identity over time is unified by an ego or a soul and this entity is indivisible and irreducible over time. Hence, according to such opposing views, personal identity over time is strict, and although psychological features may change over time, future utility still belongs to the same irreducible soul or ego and should therefore be given equal weight.

\subsection{Uncertainty}

\footnotetext{
${ }^{2}$ The work by Shane Fredrick [9] being the exception.

${ }^{3}$ See Gravelle \& Smith [13] for more detailed discussion on this matter.
} 
The uncertainty effect is the second principal argument advanced to explain why individuals' time preferences should ascribe lower weight to future benefits than to present benefits. The common way to express this effect in relation to the positive discount rate is that individuals tend to choose some good that is closer in the future because they are uncertain whether some good that lies in the more distant future will be worth as much to them (in relation to their future preferences), or indeed if they will even be around to reap the benefits of that good. Hence, for a welfare-maximising individual to account for some uncertainty it would be rational to discount future benefits at least by the probability of being alive in later periods. However, as the common expression indicates, uncertainty is not necessarily related only to mortality risk; it can also be linked to potential changes in taste i.e. value stability over time. Some events might be more or less likely to be enjoyable in the future. On a short time scale, eating is more enjoyable when you are hungry a warm sweater when you are cold, and so on. In essence, most short term changes in tastes are dependant on recent level of "consumption". Hence, we tend to be fairly accurate when anticipate such short term value instability. On a long time scale, going to the circus is probably more enjoyable as a child than as an adult, while contemporary arts and listening to the sound of the ocean is likely to become more enjoyable with age. Such long term value instability is comparably harder to anticipate.

\section{The probability argument}

A main criticism against uncertainty as a legitimate basis for discounting is that uncertainty does not necessarily follow remoteness in time. Parfit [26] proposes what he calls probabilistic discounting, arguing that we should not discount over time but over probabilities. If we discount over time we misrepresent one of the core reasons for discounting, suggesting that we attach lesser importance to what happens in the future while in fact we attach lesser importance to what is uncertain.

We ought to discount those predictions that are more likely to be false. Call this a probabilistic discount rate. Predictions about the further future are more likely to be false. So the two kinds of discount rate, Temporal and Probabilistic, roughly correlate. But they are quite different. It is therefore a mistake to discount for time rather than probability. One objection is that this 
mis-states our moral view. It makes us claim, not that more remote bad consequences are less likely, but that they are less important. [26] p. 482

What Parfit suggests is that if uncertainty is a main reason for discounting future values, then the discount rate should be differentiated depending on the risk involved in the project - not on when we can reap the benefits of some (present) cost. For health this would mean the risk of not living in the next period, which has several immediate implications. Since the risk of not living in the next period steadily increases as a person ages, this would imply a significant higher rate when discounting health benefits for older persons compared to younger persons. Similarly, disadvantaged groups with a lower probability of surviving should discount at a higher rate with probabilistic discounting.

\section{Diminishing marginal utility and growth as a basis for discounting health $\left(\varepsilon_{\mathrm{x}} \mathbf{g}_{\mathrm{x}}\right)$}

The second part of Ramsey's formula for the social discount rate stems from the combination of growth and diminishing marginal utility. In a growing economy, people will generally be better off in the future since they will have more of some relevant good. Diminishing marginal utility simply states that utility derived from a fixed unit of good will decrease as the amount of this specific good increases. Consequently, in the presence of growth, society should place higher value on present consumption, and this should be done through positive discounting. What should be noted is that marginal utility does not really say anything about the value of some good per se, but rather about its relative value. The first Dollar is not of any less value than the 1 millionth Dollar, other than in relation to some person (who already has 1 million dollars). The diminishing marginal utility element of the argument can be viewed as a link between time preference and growth, since it requires both growth in the relevant good and altered individual preferences towards a fixed unit of that good resulting from this growth.

If the argument of growth and diminishing marginal utility is applied to health, and if a future generation is healthier than the current one, this should be accounted for simply because the future generation will have more of this good (health) and will value increased health less. But it is also possible, as Gravelle and Smith [13] argue, that the relative value of health 
compared to other goods might increase over time as society becomes wealthier. This should, in such a case, be accounted for by applying a lower discount rate to health effects compared to monetary effects when discounting future values - which leads us to the unsettled issue of whether or not health and cost should be discounted at differentiated or uniform rates. Since the growth argument states that in the presence of economic growth a dollar tomorrow is worth less than a dollar today, many economists have, by extension, argued that anything convertible into money (and back again) should be discounted at an equal rate. Those who favour uniform discounting often refer to the quotation by Fuchs and Zeckenhauser [10] that "self- respecting economics should not/.../ use different rates because it is health that is being valued". The logic underlying such a statement is that the health effects in CEA must always be valued, implicitly or explicitly, in monetary terms. Hence, it would be inconsistent and misleading not to discount at a rate that is equal for health and monetary outcomes. The reason for this can be ascribed to two closely related arguments for uniform discounting: the consistency argument and the postponing paradox.

\section{The consistency argument}

The consistency argument was first presented in an article by Weinstein and Stason [35] and is still used as one of the major arguments for advocating a uniform discount rate for costs and effects. Weinstein and Stason argue that inconsistencies arise when using different rates to discount costs and effects. They state that:

The reason for discounting future life years is precisely that they are being valued relative to dollars and, since a dollar in the future is discounted relative to a present dollar, so must a life year in the future be discounted relative to a present dollar /.../ It is the discounting of dollar costs, and the assumed steady-state between dollars and health benefits, that mandates the discounting of health benefits as well as dollars. [35] p. 720 
Box 2 Numerical example: Consistency argument

Consider the following health programmes:

Programme A costs $\$ 30000$ this year and has an effect of 1 QALY this year.

Programme B costs $\$ 30000$ in year 40 and has an effect of 1 QALY in year 40.

If we assume that the monetary valuation of health outcomes remains stable over time, as the consistency argument does, it is easy to see that these two programmes should receive equal priority since their CE ratio is identical. Hence, if we want programmes A and B to receive equal priority, the discount rate of costs $(r)$ should equal that of effects $(i)$, since only then does the CE ratio of B $\left(\left(\$ 30000 /(1+r)^{40}\right) /\left(1 /(1+i)^{40}\right)=\$ 30000 / 1\right)$ equal that of $\mathrm{A}(\$ 30000 / 1)$.

In the argument forwarded by Weinstein and Stason, there is an exact equivalence regarding the $\mathrm{CE}$ ratio between the two programmes presented in Box 2. This is underlined by the assumption of a steady state relation between cost and health benefits, which implies that purchasing health benefits for dollars does not change over time. Consequently, if decision makers want to give equal priority to programmes that cost the same and yield the same benefit in a particular year (regardless of year), this can only be achieved if costs and effects are discounted at the same rate. For the purpose of remaining consistent, and to avoid confusion, health and costs should therefore be discounted at a uniform rate according to Weinstein and Stason. Williams elucidates this reasoning further:

Because it is possible, at the margin, to transform health into wealth, and vice versa, at any point in time, and since "wealth" is (ideally) allocated through time with reference to the rate of social time preference, then it would be inconsistent to apply a different rate of discount to "health" from that being applied to "wealth" (Cited in [11] p. 277)

Consequently, the consistency argument hinges on the crucial assumption that our relative valuation of health and money remain stable over time. van Hout [33] has argued that there is no obvious reason for this assumption to be true. Instead, he has suggested that discount rates for costs and effects should be based on different growth rates and the marginal utilities related to this growth. In other words, if the value of health effects grows over time at a 
different rate from our valuation of wealth, this should be incorporated in the evaluation method by using differentiated discount rates. If we abandon the constant relationship between monetary valuation and health states, the argument of consistency disappears. ${ }^{3}$

\section{The postponing paradox}

Keeler and Cretin [16] first presented the postponing paradox, which is based on the fact that if one applies lower discount rates for health outcomes than for costs, postponing any given programme will improve its $\mathrm{CE}$ ratio. Hence, for any attractive programme there is always a superior delayed programme that should be funded first. Consequently, no programmes would ever be implemented because even the initially worst postponed programme will appear better than the best immediate programme.

Box 3 Numerical example: Postponing paradox

Consider the same health programmes as in Box 2:

Programme A from Box 1 has a cost-effectiveness ratio of \$30 000 per QALY. Assuming a 5\% discount rate for costs and a zero discount rate for effects, postponing the programme by 1 year would improve its costeffectiveness ratio to $\$ 30000 /(1.05)^{1}=\$ 28571$ per QALY. Further postponement would again improve the ratio, since the cost component declines more rapidly than the effect. The paradox is therefore that a lower discount rate for effects makes infinite postponement theoretically optimal, but it is practically undesirable.

Gravelle and Smith [13] have questioned the postponing paradox as a valid argument for not using differentiated discount rates since it does not recognise "... that the CEA decision rule is inherently incomplete and cannot cope with issues of timing decisions". van Hout [33] has after discussion in similar fashion questioned the practical relevance of the postponing paradox, although he acknowledges that it might be correct in principle. He agrees that calculations based on differentiated rates (like that in Box 3) might lead to counterintuitive results. However, he argues that these theoretical conclusions have no real bearing in practice since the type of decision problem that policymakers face is not whether programme A should be implemented now or next year, but rather whether to implement programme A instead of

\footnotetext{
${ }^{3}$ See Gravelle \& Smith [13] for more detailed discussion on this matter.
} 
an already existing programme B. Hence, if decision makers have no scope to delay current budgets to future periods, selecting programmes from a ranked list cannot be blocked.

In a recent article, Nord [23] argues that the specific type of logical and arithmetic argument that the consistency argument and the postponing paradox represent has received an undeserved amount of attention in the discounting debate. Nord argues that this type of arguments are at best trivial, at worst logically flawed, but more importantly they distract attention away from the real value issues involved when making social intertemporal choices.

\section{What is the legitimate basis for discounting future values in CEA, and how might it influence valuation of health and wealth differently?}

It is evident from the empirical literature that most people care less about their future health than they do about their current health. ${ }^{4}$ From a pure welfare-maximising perspective it is also obvious that individuals have rational reasons for doing so, especially given the uncertain nature associated with future events. Still, this does not offer sufficient grounds to proclaim that society as a whole should adopt a short-sighted attitude towards the future as regards health outcomes. In fact, if we assume that it is rational from the perspective of the individual, it could still be irrational from the perspective of society. Moreover, it might also be morally impermissible. In this section, I will return to explore the first two questions raised in the introductory section: i) Which of the motives presented in the preceding sections constitute morally legitimate reasons for discounting future values in CEA?; and ii) Do these motives apply differently when making intertemporal valuations in comparing health to wealth?

Before approaching these questions it is crucial to recognise some of the conceptual ambiguity that could potentially obstruct understanding core issues related to assessing the legitimate basis for discounting health. As indicated above, it is especially important to note that arguments related to discounting do not necessarily apply equally to intrapersonal discounting and intergenerational discounting. Issues related to the legitimacy of discounting

\footnotetext{
${ }^{4}$ Even though the empirical literature on time preferences and health show a perplexing range for annual discount rates, ranging from negative values to infinity. Studies have also shown that background factors such as: health-state, gender, level of wealth and education influence individuals' revealed time preferences for health. For a systematic review of the empirical literature on time preferences for health, see [4].
} 
in the intrapersonal setting stem principally from questions relating to individual rationality and justifiable cases of paternalism. Issues related to the legitimacy of discounting in the intergenerational setting stem principally from questions relating to fairness and limits of democracy. Recognising this conceptual ambiguity, and raising awareness about it, should help improve the quality of the discourse on discounting. Much of the literature on discounting fails to recognise the distinction between intrapersonal and intergenerational discounting, and authors frequently use the same concepts in referring to different underlying phenomena. In the economic literature, discounting is most often discussed in an intrapersonal context and justified by appealing to concepts of growth and diminishing marginal utility. In the philosophic literature, however, discounting tends to be discussed mainly in an intergenerational ${ }^{5}$ context. Much of the disagreement concerning discounting, especially in the discourse between economists and philosophers (where typically philosophers find it impermissible while economists find it inevitable), seems to stem from differences in the discounting perspectives they apply. Misunderstanding is the inevitable result. Equivocal $\mathrm{f}$

The pure preferences effect is the first argument advanced to explain why individuals' time preferences should ascribe lower value to the future. It could be argued that a societal discount rate in a democratic society should reflect the preferences of its current citizens, and if they for whatever reason feel that the present is more important than the future, this is the attitude that society should adopt (see e.g. [21]). This type of appeal to democracy, however, lends little support to the claim that pure time preference is a morally permissible basis for intergenerational discounting, since the future generations affected by present choices will have no vote. When discussing time preferences we are generally referring to individuals' personal preferences within their own lifespan. When incorporating the pure time preference effect as a legitimate basis for social discounting, however, we also assert that the welfare of future generations is less important than that of present generations. Intuitively this seems impermissible from a fairness perspective. Few people would, for example, proclaim that it is morally permissible to apply a spatial discount rate that assigns a lower value to benefits that accrue on individuals at a further distance, based on remoteness in miles ${ }^{6}$. The fact that current generations favour themselves over future generations, and are therefore willing to

\footnotetext{
${ }^{5}$ What constitute a generation is not always clear. I will here refer to a generation as a group of people born in certain interval, which implies that several generations coexist at a specific point in time. The alternative interpretation would be to refer a generation to those people alive during a specific interval, which would imply that an individual's life instead extends across several generations.

${ }^{6}$ The fact that we often do so implicitly anyway is another matter.
} 
impose greater burdens on future generations to avoid lesser burdens on their own, cannot be considered an ethically valid basis for discounting - particularly as regards policymakers who are supposed to adopt an impartial stance and protect the interests of all individuals in society, current and future generations alike ${ }^{7}$. Consequently, there is a strong argument against populist forms of democracy as processes for deciding social discount rates. Democracy is, in essence, a system for respecting citizens' political preferences. Contemporary democracy is insufficiently sensitive to the concerns of future generations if individuals in general tend to favour themselves over future generations, which seems highly plausible. Considering that the life span of governments is usually much shorter than the life span of individuals, this would entail directing attention to decisions that have immediate and visible effects as opposed to more long-term effects, implying a high discount rate. A potential way for policymakers to resolve the conflict between democracy and the concern for future generations is to increase the technical complexity of the issue, preventing people from understanding the serious practical implications that the social discount rate can have. I would argue that this is what has happened in the case of discounting. Discounting is often portrayed (deceptively I would say) as a highly technical matter, and this has had obvious consequences for transparency with respect to the value judgements it involves.

Still, some could object that many policy decisions affect only current generations, and in such scenarios it cannot be considered morally impermissible to favour the present over the future. This objection has some bearing and moves us towards the issue of irrationality and paternalism in discounting - an issue that I will return to in the next section. For the moment, I will assume that the behavioural effects that together form individual time preferences as a basis for discounting future health constitute rational reasons for discounting future health from an intrapersonal perspective. However, when comparing the pure time preference effect between health and wealth in the intrapersonal context, it should be noted that although most individuals reveal positive time preferences in empirical studies, this is not necessarily true for all individuals or all choices [32]. Moreover, the fact that most individuals reveal positive time preferences does not necessarily mean that they also have positive pure time preference, since it is difficult to single out the pure time preference effect from other effects in empirical studies. I would argue that pure time preferences for health are more likely to be negative

\footnotetext{
${ }^{7}$ It should be noted that this argument hinges on the assumption that future generations have an ontological status, which is equivalent to current generations. Absent that, they cannot have rights and one cannot be fair/unfair to them This assumption could be debated, but will not be further addressed in this paper.
} 
compared to monetary values, since individuals might prefer ill-health sooner rather than later in order to eliminate dread - just as some individuals prefer to postpone future monetary benefits in order to derive pleasure from anticipation. Consequently, there is no prima facie reason for assuming that the pure time preference effect should apply equally to health and wealth in the intrapersonal context.

The uncertainty effect is a second argument advanced to explain why individuals' time preferences should ascribe lower value to future outcomes. From an intrapersonal perspective it could be argued that given the brevity and uncertainty of human life, it is rational to attribute less value to future events than to immediate ones if they have a different probability of occurring. Also, the more distant an event, the less certain we are likely to be about its value to us, i.e. value instability. Both of these factors are clearly relevant when making intertemporal decisions in the intrapersonal context. Although, it should be noted that there are longitudinal data that indicate that individuals have remarkable value stability over time when it comes to health choices $[5,20]$. Analogously, when making intergenerational policy recommendations, society ought to take into account that predictions about the future are less likely to be true. However, I would argue that the proper way of dealing with uncertainty over time in CEA is not through the social discount rate, regardless of perspective. When conducting CEA, we typically assume that measures of uncertainty are incorporated through life tables and other parameters of uncertainty regarding future consequenses. For that reason, taking uncertainty into account when assigning a societal discount rate would present a case of double counting. Another strong reason for not dealing with uncertainty through the social discount rate is that uncertainty often correlates poorly with time and is highly unstable across different groups of individuals. For example, the mortality risks associated with the old or disabled are much higher than for the young and healthy. Although we may want to consider this when making intertemporal policy decisions, including uncertainty as a basis for discounting would mis-state our moral view - it makes the statement that remote events and older people are less important, but what we want to state is that those events are less likely.

As with pure time preferences, there seems to be no prima facie reason for assuming that the uncertainty effect should apply equally to health and wealth in the intrapersonal context. Uncertainty associated with future monetary outcomes involves more than the risk of early death. There is also the risk (or opportunity) that individuals might live an unexpectedly long 
life, in which case it would be rational to save benefits needed for future consumption. Consequently, the uncertainty effect, as regards future wealth, might influence the discount rate not only in the direction of putting less value on future goods, but also by putting higher relative value on future goods. In addition, at least two substantial differences regarding uncertainty are found between health and wealth, which could cause them to differ further. First, although individuals cannot insure themselves against their own death, they can insure themselves against future loss of wealth. This makes the uncertainty effect potentially higher for health compared to wealth. Second, regarding wealth, some utility arises from bequests when a person suffers an early death. This bequest effect is not applicable to health, and could potentially increase the uncertainty effect in health compared to wealth.

When discussing the role of uncertainty in an intergenerational context, we should note that uncertainty is likely to have much less impact at the societal level compared to the individual level. Societies are not mortal in the same sense that individuals are. Although, potential natural catastrophes and nuclear wars may invoke some uncertainty regarding survival of society at large, this is very different from the individual perspective where death is an inevitable fact, and the risk of being absent in the next time period steadily increases as one gets older. Consequently, the argument for discounting arising from uncertainty is not as valid when applied to social decision making in contrast to individual decision-making.

The combined argument from growth and diminishing marginal utility possibly presents the strongest reason why society should apply a positive discount rate in both the intrapersonal intergenerational context. However, this hinges on the assumption of continuous growth in the relevant good, implying that we derive more satisfaction from any given unit of a good now rather than later, if we have more of it in the future. To avoid redistribution from a present that is relatively poor, to a future that is relatively rich, one can make a strong fairness argument for encouraging discounting in the presence of growth. However, in the absence of growth this fairness argument disappears. In the case of recession, the logic of growth and diminishing marginal utility would, on the contrary, imply that we should redistribute from the relatively rich present to the relatively poor future. Hence, if we expect individuals or future generations to be worse off in terms of the relevant good in the future (ceteris paribus), society should assign a negative discount rate if the rate is to be based solely on the marginal utility effect. 
As with pure time preferences and uncertainty, there appears to be no prima facie reason to assume that the combined argument from growth and diminishing marginal utility should apply equally to health and wealth in an intrapersonal context. Regarding health, most people expect to be less healthy as they grow older due to natural ageing. In such a scenario the effect of diminishing marginal utility would imply that future health benefits will be of higher relative value to individuals since we can assume that people generally become less healthy the older they get. Regarding wealth, in contrast, most individuals do not anticipate becoming less wealthy the older they get. Consequently, in the intrapersonal context the combined argument from diminishing utility and growth moves in opposite directions for health compared to wealth. For intergenerational discounting, this difference between health and wealth seems less obvious since we are dealing with the future life of others and not our own stock of health or wealth.

\section{The time-relative relationship between health and wealth}

As shown in section 4 justifications for applying a uniform discount rate for health outcomes and costs in CEA are usually underpinned by a consequentialistic rationale, i.e. that the consequences of not discounting or discounting at a differential rate would generate unaccaptable outcomes. However, it is important to notice that neither the postponing paradox nor the consistency argument present arguments for discounting future health per se, but arguments why health should be discounted at the same rate as cost. Both the arguments implying that the use of differential discounting would lead to policy recommendations considered to be undesirable and inconsistent. The reason given is that outcomes from CEA would be such that beneficiaries, who are identical in all relevant aspects except for their position in time, would be assigned unequal CE ratios when present values are calculated. However, Just as Nord [23] argue, these objections are somewhat misplaced since it does not follow from consistency or logic that decision makers should be indifferent with respect to when health benefits occur.

Both the postponing paradox and the consistency argument rely on the crucial assumption of a steady state relationship between money and health - i.e. the constant value of a unit of health (e.g. QALY or DALY). This assumption appears to hinge on convenience rather than 
reflection. Whether or not the growth rate for health and wealth is the same is an empirical question. But given the special nature of health compared to other goods, it does not seem unreasonable to believe that the growth rate for health could differ substantially from the growth rate elsewhere in the economy. And if the relationship between health and wealth is indeed unstable over time, and we fail to take this into account, Pareto-dominated health programs might be recommended for implementation on the basis of CEA. Hence, if the relative valuation of health increases over time, society should correct for this through differential discounting to reach proper conclusions regarding the relative welfare improvements of different health care interventions. By doing so we may find that we have to re-evaluate the normative consequential framework underpinning CEA.

\section{Normative relevance of individuals' time preferences}

The normative relevance of empirical insights regarding elicited time preferences crucially depends on whether or not they address the question they are intended to inform. Harsanyi [14] suggested that individuals have two sets of preferences - one set that reflects individuals' preferences for their own wellbeing and a second set where individuals (in the role of citizens) take social considerations into account. These two sets of preferences may come into conflict, which complicates the concept of welfare maximisation. More specifically, it is highly likely that individuals' time preferences for their own health differ from the preferences they (in the role of citizens) have for social intertemporal choices of health. Hence, just as it was important to recognise the conceptual distinction between intrapersonal and intergenerational discounting when assessing the legitimate basis for discounting, it is necessary to recognise the distinction between personal and societal time preferences when discussing the normative relevance of individuals' time preferences in the context of the social discount rate.

The basic difference is that personal time preferences refer to those preferences elicited by asking individuals to make intertemporal choices regarding themselves, while social time preferences involve making intertemporal choices from the perspective of society at large. ${ }^{8}$ Consequently, social time preferences encompass both intrapersonal and intergenerational setting, while personal time preferences is analogous with the intrapersonal setting. Personal

\footnotetext{
${ }^{8}$ Note that it is possible to combine these two perspectives when eliciting preferences. This could for example be done by asking: "What value do you attach to future utility for a group of people amongst whom you might find yourself?" See [6] for further discussion.
} 
time preferences are well in accordance with the individualistic foundations of welfare economics. The traditional wisdom amongst economists has been that individuals have clear, well-defined preferences, and societal value is maximised when aggregating these personal preferences (utilities) within a community. In recent years, however, interest has increased amongst economists for eliciting individuals' societal preferences [24]. The rationale for this is that personal preferences do not incorporate the distributional concern that individuals might have for others, and when allocating resources within a policy context such distributional concerns have substantial relevance. Given that CEA primarily aims at informing decision makers when dealing with allocation at a population-level, it seems illogical that personal time preferences regarding their own health should be used as input. Instead, it seems reasonable to argue that individuals' societal preferences are the ones most relevant when discussing the basis for social discount, since choices between competing health care programmes are social choices, not private ones.

\section{Preference failures and paternalism}

So far I have dismissed pure time preference as a morally permissible basis for intergenerational discounting since it would lead to unfair allocations between generations. But let's return to the objection that many policy decisions are intragenerational, i.e. they affect only current generations. In intragenerational discounting, it is difficult to see why favouring the present over the future should be considered morally impermissible. Libertarians have long argued that although individuals' choices will not always maximise their own wellbeing, they remain the best judges of how to satisfy their own preferences. From a general perspective it is hard to disagree with this claim - why should the state or someone else be a better judge of my welfare? Indeed, one of the underlying value judgements for achieving Pareto optimality is that individuals are the best judges of their own welfare. However, from a less general perspective it is obvious that this claim is not true in all cases. Paternalism might be justified in some non-standard cases.

Paternalism is generally viewed as state action directed towards the individual against their will, motivated by a claim that the affected person will be better off or protected from harm [7]. Consequently, the issue of paternalism requires careful balancing of which value, respecting subjects' autonomy or increasing subjects' overall well-being, is more important in 
the case at hand. A necessary (although not necessarily sufficient) prerequisite for justifying paternalism is that the state in fact has a better conception of what constitutes welfarepromoting actions than what stems from individuals' basic aims and values. In economics, preferences based on insufficient information or inadequate facts are generally viewed as market failures where society are obliged to intervene. For instance, if a harmful drug is put on the market, the state should take action to prevent individuals from unknowingly taking it. The inefficient outcome of taking harmful drugs would otherwise be a result of individuals' inability to assess how to promote their own welfare. This type of paternalism, where the individual is not regarded as a fully capable decision maker, is generally considered justifiable even among libertarians. In the case of positive pure time preferences, however, we are dealing with individuals who act in an imprudent or shortsighted manner while fully understanding the future consequences of their behavior. In these cases, state intervention is harder to justify than in the case of market failure. Consequently, we are confronted with the question when, if ever, is it justifiable for policymakers to override individuals' fully informed preferences?

From an economist's perspective, the obvious answer would be that it is justifiable to override an individual's fully informed preferences when it increases the individual's welfare. Hence, we need to identify those preference failures (as opposed to market failures), where individuals sufficiently fail to act in their own best interest. For positive pure time preferences there are two typical categories of preference failures that might help justify paternalistic state interventions to correct for the individual's fully informed preferences. I will label these two categories myopic and acratic preference failures.

The first category, myopic preference failure, relates to a cognitive inability to compute information adequately to make choices that maximise the welfare of the individual. This typically refers to cases where the logical or causal connections between choice and outcome are difficult to make [12], or alternatively to cases where the quantity of information is too great for the individual to assess [22]. The information itself might, however, be perfectly adequate. Judgments about probabilities and likely future outcomes of actions are particularly common in this category of preference failure. The work of Tversky and Kahneman [15] has shown empirically how people with perfect information commonly display inadequate reasoning power to interpret and calculate the implications of certain statistical or probabilistic situations. This further strengthens the argument that individuals' assessment of 
uncertainties associated with their own future should not be a basis for the social discount rate.

The second category, acratic preference failure, relates to reduced willpower. This refers to instances where individuals act against their own better judgment and fail to do what is in their long-term best interest. It could, for example, include cases where the individual often lacks the ability to emotionally assess the force of information - knowing the facts, but not feeling the force of an outcome psychologically. Hence, even though these individuals might make good judgments as to what is necessary to optimise welfare, they still frequently choose a different course of action. For example, people who maintain an unhealthy lifestyle often assert that they would like not to engage in unhealthy activity, but find it impossible to stop doing so due to an insufficient capacity to self-regulate. Another example of acratic preference failure would be individuals that spend their money in the pub or on luxury goods rather than future necessities, despite being fully aware of the negative long-term effects this will have on their welfare. An analogous way of explaining acratic preferences would be to say that individuals have 'preferences for preferences' and acrasia occurs when their secondorder evaluative desires differ from their first-order motivational desires [8]. Thus, individuals wish that their immediate preferences would be different from what they are, and in such cases paternalism could be justified on the grounds that the state is merely respecting a person's own higher preferences.

In many countries, this line of argument is commonly used to motivate mandatory public programmes to ensure individual saving for retirement and avoid procrastination, or to deny an addicted person's preferences once he or she has checked into a rehab center.

The main difference between myopic and an acratic preference failure is that myopia involves a systematic tendency to overestimate the value of earlier benefits in comparison to later benefits. A myopic individual sincerely believes that he or she is making a correct choice when choosing a smaller early benefit instead of a larger later benefit. But the individual's tendency of imprudence leads to choices that give inadequate weight to future events. An acratic individual is well aware that he or she will prefer a later benefit, but still choose the early benefit rather than the later one. From an economist's perspective, both myopic and 
acratic preferences are by definition irrational since they are associated with regret in the sense that individuals wish they had chosen differently retrospectively.

Acrasia can be further linked to Parfit's reductionist account on personal identity, which provides a plausible explanation for why this seemingly irrational behaviour is, in fact, rational. Parfit's claim is that although being fully informed, individuals might be truly unable (psychologically) to resist the temptations of choosing immediate benefits rather than greater benefits later even though their judgment says that this is not the best option. According to Parfit, a person may be truly unable to act in coherence with his or her fully informed judgment since the psychological link with the future self is too weak, making such preferences fully rational. However, this has no immediate implications for the view presented here of when paternalism is justifiable since the existence of acratic preferences would be categorised as market failures (negative externalities) due to the inability of some persons affected by the decision (future selves) to participate in the decision-making process. With Parfit's account of personal identity, acrasia transcends from being an issue of irrationality to being an issue about fairness. Arguably, fairness would be a stronger justification for overriding informed preferences than irrationality would. Moreover, according to the Parfitian view of identity, no paternalism is involved when overriding individuals time preferences since it would merely be a case of protecting the rights of future selves, which have the status of other people.

In cases where individuals' preferences suffer from myopia or acrasia, society occasionally would have an advantage over the individual in appreciating what is in that individual's best interests in the long term. Decisions that involve weighing future benefits against present ones offer both a significant temptation to satisfy immediate wants above those with long-term benefits (acrasia) and unusual technical difficulties involving probabilities that make it hard for individuals to compute the actual trade-off (myopia). By extension, if policymakers have the knowledge that most individuals would like to change their choices ex post it would not be a case of overriding individuals' informed preferences. Instead, it would merely be a case of giving some of the person's own preferences less consideration than others in attempting to prevent individuals from being caught short by their own inconsistent patterns of pure time discounting. Hence, this softer kind of paternalism aims primarily at helping people make choices that are congruent with their long-term interests. 
To conclude, a person's immediate preference satisfaction does not necessarily coincide with a person's good when it comes to intertemporal choices. Hence, some laundering of preferences characterised by myopia and acrasia intuitively seems both necessary and legitimate when discounting future values (for both health and monetary outcomes) in a welfare-promoting society. We must acknowledge, however, that the idea of positive pure time preferences is not self-evidently connected to market or preference failures. Just as people might prefer red wine to white wine, or a Big Mac to a Whopper, they could have a similar preference for the present compared to the future. Two aspects related to today's preferences about future events are particularly relevant when assessing the value of the future state of affairs. The values placed on anticipation and dread are experienced in the present, and I would argue that these are values that do not stem from myopia or acrasia. We often postpone things of a good nature to experience good value from anticipation. Likewise, at times we choose to bring forward unpleasant events, not because we expect them to be less unpleasant, but because we want to avoid dread. For intrapersonal discounting, individuals' pure time preferences could potentially constitute a legitimate basis for discounting future events once such preferences have been laundered from myopic and acratic elements.

\section{Final non-utilitarian remarks about cost-effectiveness analysis and discounting}

This article has been written mainly from a traditional utilitarian perspective. As an economist, I feel most comfortable within this type of framework since maximising welfare offers a straight-forward solution regarding which policies to recommend. However, I would argue that it is worth stepping outside of the traditional framework of utilitarianism when considering the issue of discounting future health. If the societal objective in making intertemporal choices is solely to maximise net welfare over time, this could easily lead to a very unequal distribution across generations, forcing one generation to make excessive sacrifices for the sake of future generations. For example, it would be unjust to require the current generation to commit itself to large-scale medical experiments with severe immediate consequences for the purpose of benefiting future generations - even though this would increase the net sum of welfare over time. No generation can be morally obligated to exceed a certain level of sacrifice for the sake of future generations. This is an issue that the utilitarian framework for discounting within CEA does not consider - but then, CEA in general 
Legitimate basis for discounting

incorporates little or no consideration for how to distribute burdens or benefits. Costeffectiveness analysis does not reflect every aspect of importance in the allocation of scarce health care resources, which could be considered a weakness if one chooses to view CEA as a decision rule rather than decision input. In my opinion, the future credibility of CEA as valid input to intertemporal public policy hinges on its ability to be transparent in the value judgments it incorporates. Decisions regarding allocation of health care resources (temporal or not) involve balancing of conflicting moral values on which reasonable people will disagree. Therefore, rather than trying to incorporate distributional and other non-utilitarian concerns into the CEA, we should keep these concerns separate while concurrently informing decision makers in a manner that makes inevitable moral judgments as transparent as possible.

\section{References}

[1] Baumol, W. J. (1968) On the social rate of discount. American Economic Review 81, 334-340.

[2] Brouwer, W., Niessen, L., Postma, M. \& Rutten, F. (2005) Need for differential discounting of costs and health effects in cost effectiveness analyses. British Medical Journal 331, 446-448.

[3] Cairns, J. \& M. Van der Pol. (1997) Constant and decreasing timing aversion. Social Science and Medicine 45, 1653-1659

[4] Cairns, J. (2006) Developments in discounting: With special reference to future health events. Resources and Energy Economics 28, 282-297.

[5] Caspi, A., Begg, D,. Dickson, N,. Harrington, H,. Langley, J., Mofitt,T. \& Silva, P,. (1997) Personality differences predict health-risk behaviors in young adulthood: Evidence from a longitudinal study. Journal of Personality and Social Psychology 73, 1052-1063

[6] Dolan, P., Olsen, J. A., Menzel, P. \& Richardson, J. (2003) An Inquiry into the different perspectives that can be used when eliciting preferences in health. Health Economics, 12, 545-51. 
Legitimate basis for discounting

[7] Dworkin, G. (2010) Paternalism. In Zalta, E. N. (Ed.) The Stanford Encyclopedia of Philosophy (Summer 2010 Edition).

[8] Frankfurt, H. (1971) Freedom of the will and the concept of a person. Journal of Philosophy, 68, 5-20.

Fredrick, S. (2003) Time Preference and Personal Identity. In Loewenstein, G., Read, D. \& Baumeister, R. F. (Eds.) Time and decisions. New York, Russel Sage Foundation.

[10] Fuchs, V. \& Zeckenhauser, R. (1987) Valuing health- a "priceless" commodity. American Economic Review 77, 263-68

[11] Gold, M. R. (1996) Cost-effectiveness in Health and Medicine. New York: Oxford University Press.

[12] Goodin, R. (1993) Democracy, preferences and paternalism. Policy Sciences 26, 229-47.

[13] Gravelle, H. \& Smith, D. (2001) Discounting for health effects in cost-benefit and cost-effectiveness analysis. Health Economics 10, 587-99.

[14] Harsanyi, J. (1955) Cardinal Welfare, individualistic ethics and interpersonal comparison of utility. Journal of Political Economy 63, 309-321.

[15] Kahneman, D. \& Tversky, A. (1979) Prospect theory: An analysis of decisions under risk. Econometrica 47, 313-327.

[16] Keeler, E. \& Cretin, S. (1983) Discounting of life-saving and other nonmonetary effects. Management Science 29, 300-306.

[17] Korsgaard, C. (1989) Personal identity and the unity of agency: A Kantian response to Parfit. Philosophy and Public Affairs. 18, 101-132.

[18] Krahn, M. \& Gafni, A. (1993) Discounting in the economic evaluation of health care interventions. Medical Care 31, 403-18. 
Legitimate basis for discounting

[19] Laibson, D. (1997) Golden Eggs and Hyperbolic Discounting. Quarterly Journal of Economics, 112, 443-477.

[20] Levin, I., Hart, S., Weller, J., \& Harshman, A. (2007) Decision-making task: A 3-year longtidudinal study with children and adults. Journal of Behavioural Decision Making 20, 241-252.

[21] Marglin, S. A. (1963) The social rate of discount and the optimal rate of investement. Quarterly Journal of Economics 77: 95-111.

[22] New, B. (1999) Paternalism and public policy. Economics and Philosophy 15, 63-83.

[23] Nord, E. (2011) Discounting future health benefits : the poverty of the consistency arguments. Health Economics 20,16-26.

[24] Nord, E., Pinto, J., Richardson, J., Menzel, P. \& Ubel, P. (1999) Incorporating s ocietal concerns for fairness in numerical valuations of health programmes. Health Economics, 8, 25-39.

[28] Ramsey, F. (1928) A mathematical theory of saving. The Economic Journal 38, 543-549.

[29] Rawls, J. (1971) A Theory of Justice. Cambridge, Massachusetts; Belknap Press.

[30] Samuelson, P. (1937) A Note on Measurement of Utility. Review of Economic Studies 4, 155-161.

[31] Sidgwick, H. (1874) The Methods of Ethics. London: Macmillan and Co. 
Legitimate basis for discounting

[32] van Der Pol, M \& Cairns, J. (2000) Negative and zero time preference for health. Health Economics 9, 171-175.

[33] van Hout, B. (1998) Discounting costs and effects: a reconsideration. Health Economics 7, 581-94.

[34] van Liedekerke, L. (2004) John Rawls and Derek Parfit's critique of the discount rate. Ethical Perspectives 11, 72-83.

[35] Weinstein, M. \& Stason, W. (1977) Foundations of cost-effectiveness analysis for health and medical practices. New England Journal of Medicine 296, 716721.

[36] Williams, B. (1970) The self and future. Philosophical Review. 79, 161-180 